\title{
The Importance of Green Energy Consumption and Agriculture in Reducing Environmental Degradation: Evidence From Sub-Saharan African Countries
}

\author{
Gholamreza Zandi ${ }^{1} \&$ Muhammad Haseeb ${ }^{2}$ \\ ${ }^{1}$ Universiti Kuala Lumpur Business School, Malaysia \\ ${ }^{2}$ Taylors Business School (TBS), Taylors University Lakeside Campus, Selangore, Malaysia \\ Correspondence: Dr. Muhammad Haseeb, Taylors Business School (TBS), Taylors University Lakeside Campus, 1 \\ Jalan Taylors Subang Jaya Selangore, Malaysia.
}

Received: April 30, 2019

doi:10.5430/ijfr.v10n5p215
Accepted: May 30, 2019

Online Published: June 10, 2019

URL: https://doi.org/10.5430/ijfr.v10n5p215

\begin{abstract}
In recent period of energy focus countries have paid more consideration to the argumentative topic of green energy in both developed and developing economies. Renewable energy is also called green energy. It is described as the energy that is collected by renewable bases of wind, waves, geothermal, sunlight, heat and rain etc. and gives least harm to the nature and environment. The rapid placing of green energy is providing a noteworthy economic profit, energy security and environment change mitigation. Therefore, this current research investigates the association of green energy consumption with environmental degradation by utilizing panel data of 35 sub-Saharan African countries from 1995 to 2017. Moreover, we utilize the advanced panel techniques to investigate the cross-section independence. We also apply CIPS unit root test, Westerlund (2007) bootstrap cointegration, Panel Pedroni and Kao co-integration, FMOLS, DOLS and heterogeneous panel causality methods. The results confirm that all factors are connected in the long-term period. The outcomes also explain that the green energy utilization has a negative impact on environmental hazards and support to decrease environmental hazards. Likewise, globalization has a positive and significant effect on environmental hazards. Also, the agriculture productions also play a significant and positive impact on environmental degradation. Finally, the heterogeneous panel causality confirms a bi-directional causal relationship between green energy consumption and environmental degradation in all sub-Saharan African countries. This current research offers valuable strategy suggestions for the management and the policymakers.
\end{abstract}

Keywords: green energy, agriculture production, environmental degradation, Sub-Saharan African countries, panel estimations

\section{Introduction}

Witnessing the growing global warming and deteriorating environmental condition, the economies at present are facing enormous pressures for pursuing economic advancements along with sustainable ecological environment. In this regard, the contribution of energy is considered critical for aiding the process of economic development, however, carrying multiple adverse effects on the environment (Akella, Saini, \& Sharma, 2009; Olowa, 2018). The toxic emissions resulted from the burning of fossil fuels and other non-renewable forms of energy such as natural gas, gasoline, heating oil etc., in several industrial processes put enormous pressure on the environment by releasing carbon-di-oxide, Sulphur Dioxide, dust \& aerosols, nitrogen oxides, steam-laden emanations along with damaging ozone layer (Akella, et. al, 2009; Olufemi, 2018). The surging levels of pollutions have been regarded as the failing outcome of many industries, however, in the current environmental era, the attentions have been diverted towards eco-improvements.

Following the supreme emphasis of the international world on the notion of sustainable development, businesses in diverse industries are enduring numerous drives for adopting eco-friendly corporate practices to play their due part in ecological improvements (Leonidou, Fotiadis, Christodoulides, Spyropoulou, \& Katsikeas, 2015; Önder, 2018). In addition to raising awareness for ecological health, the mounting environmental laws are also one of the several reason for businesses to accept the objectives of sustainability in order to remain functioning without facing any legal consequences (Bosselmann, 2016; Onyinye, Jonathan \& Emmanuel 2018). Moreover, growing consumer demand for 
eco-friendly goods and services are also among the motivations for businesses to contribute in decreasing environmental pressures by adopting environmentally responsive business methods (Zhang, Zhou, Liu, \& Lu, 2019).

Given the enormous dependence of economies on energy consumption, in various sectors of manufacturing, technologies, transportation, agriculture, communication etc., it seems challenging for the countries to find alternatives of energy in their operations. In addition, the households' consumption of energy is also considered a basic necessity and the eminent part of societal development (Xiaohua, \& Zhenmin, 2001; Onyinye, et.al 2018). Under such conditions, the replacement of harmful energy from green sources can be productive for both economic and environmental improvements. In this vein, the consumption of renewable sources of energy are regarded as the efficient solution of fulfilling energy needs of the commercial and households without disrupting environment (Mittal, Dai, Fujimori, \& Masui, 2016; Widarjono, 2018). By definition, Green or renewable energy is regarded as the form of energy that is derived from eco-friendly sources, such as sun, wind, water, woods etc., that exert neither pressure on the environment. The utilization of green energy for fulfilling the needs of industries and households would be successful in capturing the benefits of energy as an input and the substantial driver of economic prosperity (Ocal, \& Aslan, 2013; Apergis, \& Payne, 2010; Amponsah, et. al., 2014; Wang, 2016).

The crucial relationship of green energy with carbon emission has been widely accepted for improving environmental quality by reducing the toxic greenhouse gas emanations. In this regard, many studies conclude the negative association of green energy consumption and carbon emission (Inglesi-Lotz, \& Dogan, 2018; Zoundi, 2017; Bento, \& Moutinho, 2016). However, there also exists some investigations that reported the positive link among the variables making the association critical to examine (Jebli, \& Youssef, 2017; Orji, Ogbuabor \& Anthony-Orji 2018). The utilization of green sources of energy are apparent to bring improvement in environmental quality, however, the utilization of carbon based installation of green projects carry negative effects on ecological condition. In such conditions, green energy may become the culprit of worsening environmental quality. Moreover, many economies have initiated the utilization of renewable energy consumption by installing mass green projects including solar plants, hydro vessels, wind energy investments etc., but they are unable to switch from the traditional sources of power generation and still heavily depend on fossil based energy. This led to diminish the impact of green energy in supplementing eco-improvements.

Another crucial feature for ensuring environmental quality is the advancements and processes in agriculture. In this regard, the role of agriculture is also considered eminent in curtailing ecological disruptions (Reganold, \& Wachter, 2016; Liu, Zhang, \& Bae, 2017; Orji, et. al., 2018). The dependence on agriculture often discourage other industrial expansions and safeguards from several adverse by-products of pollution and resource depletion. Moreover, with the rise in environmental awareness, farmers have become habitual of making the best use of their environment with superior, eco-friendly and locally adapted agricultural systems that carry several social and environmental benefits. In addition, plants and trees in farming aid to hold and pour water to underground aquifers. Together, they go about as an imperative tool for reducing the occurrence of flooding and also protect from water pollution along with the obvious benefit of producing nutritious foods, local jobs and pleasant habitat.

Given the significance of agriculture in Sab-Saharan African (SSA), the ranchers in the region utilize couple of present day contributions notwithstanding the way that most hardship decreasing rural development in the area is relied upon to come to a great extent from extended utilization of advanced methods such as improved seed, composts and other agro-synthetic compounds, tools, and irrigation (Sheahan, \& Barrett, 2017). Similarly, the consumption of renewable energy is also found as the prime focus in SSA countries. The emerging focus on green projects including solar power generation has been given vital importance in the region (Amankwah-Amoah, 2015). In addition to the environmental benefits, the utilization of green energy is also beneficial in Sab-Saharan region from the economical aspect. Given the severe poverty and lack of development, the region heavily relies on agriculture but above 600 million people of Africa lack the basic necessities such as water and electricity (Arcanjo, 2018). The utilization of renewable sources of power generation is considered productive in the region for having economic benefits of cheap cost, low investment requirement and ease of installation (Sims, Rogner, \& Gregory, 2003; Osabohien,et.al 2018). Moreover, the utilization of clean energy supply is considered beneficial for poverty alleviation and economic prosperity of the region (World Bank, 2001). Therefore, the region of SSA is crucial for examining the potential link of renewable energy consumption and carbon emission (Deichmann, Meisner, Murray, \& Wheeler, 2011; Winarni, et.al 2018).

Thus, understanding the crucial role of green energy and agriculture in influencing environmental health, the present study aims to examine the impact of green energy consumption and agriculture value added on environmental degradation in Sub-Saharan African region. The significance of current study is attributed in identifying the eminent 
role of renewable energy utilization in changing the levels of toxic carbon emission in the sampled nations. Furthermore, the methodological contribution in the current examination is also notable in applying advanced methods to explore the critical association among the variables of interest. In doing so, the current investigation applied the econometrics of panel Fully Modified Ordinary Least Square (FMOLS) and Dynamic Ordinary Least Square (DOLS) along with examining the cross-sectional dependence and Bootstrap cointegration. Hence, the understandings resulted from such sophisticated methods would enhance the authenticity of the derived findings and would help building efficient environmental policies.

The remaining article is outlined as below. Section II displayed the review of the prevailing studies. Section III presents the description of the applied methodology. Section IV demonstrates the research findings. Section V concludes the outcomes and presents policy implications.

\section{Literature Review}

Several studies have discussed the important link of energy with economic growth. In recent literature, the focus is shifted towards environmental impact of energy and emphasized on the relationship of conventional energy with environmental degradation by considering the role of fossil fuels based energies and carbon emissions. In a more recent literature, many studies examined the association between renewable of green energy and agriculture with carbon emanations. Among them, Bilgili, Koçak, and Bulut, (2016) inspected the association of renewable energy and output growth with environmental degradation. In order to measure degradation, the authors used the measure of carbon-di-oxide emanation. The study used the data of seventeen OECD nations from the period of 1977 to 2010. Applying the econometrics of panel FMOLS and DOLS, the outcomes of the study revealed that renewable energy is significant to influence environmental degradation. Specifically, the findings established that increase in green energy is vital to reduce the carbon emanations in the sampled countries. Moreover, the results also supported the validity of EKC curve indicating an inverted $\mathrm{U}$-shaped association.

In ASEAN region, Liu, et al., (2017) also inspected the association of green energy, non-renewable energy and agriculture with environmental degradation. In order to measure degradation, the authors used the measure of carbon-di-oxide emanation. The study used the data of four ASEAN economies from the period of 1970 to 2013. Applying the econometrics of panel cointegration, FMOLS and DOLS, the results of the study revealed that all the variables are significant to influence environmental degradation. Specifically, the findings established that increase in green energy and agriculture is vital to reduce the carbon emanations, however, non-renewable consumption enhanced it. Moreover, the results also supported the validity of EKC curve indicating an inverted U-shaped association. The results of causal investigation also suggested the presence of causal relationship among energy and carbon emanations suggesting the bi-directional causal links among green energy, non-renewables and environmental degradation in the sampled countries.

In another study, Apergis, \& Payne, (2015) analyzed the connection between renewable energy, oil prices, output per capita and environmental degradation. In order to measure degradation, the authors used the measure of carbon-di-oxide emanation. The study used the data of eleven South American economies from the period of 1980 to 2010. Applying the econometrics of panel cointegration and error correction model, the outcomes of the study revealed that output per capita, oil prices and carbon emanations are significant to influence environmental degradation. Specifically, the findings established that increase in the variables brought positive impact on green energy utilization in South American economies. Moreover, the results of causal investigation suggested the presence of bi-directional relationship among green energy and output in both short and long-run. As for, carbon-di-oxide and green energy, the results found that in short run, the rise in emanations resulted into augmented green energy utilization, however, increase in green energy declined the levels of carbon emanations. The results of oil price and green energy also established that rise in oil price enhances green energy and vice versa.

Similarly, Zoundi, (2017) also investigated the link between renewable energy, output growth and environmental degradation. In order to measure degradation, the author used the measure of carbon-di-oxide emanation. The study used the data of twenty five African nations from the period of 1980 to 2012. Applying the econometrics of panel cointegration and DOLS, the outcomes of the study revealed that renewable energy is significant to influence environmental degradation. Specifically, the findings established that increase in green energy brought negative effect to the levels of carbon emanations in the sampled countries. Unlike Bilgili, et al., (2016), the results failed to support the complete validity of EKC curve for the case of African countries. Moreover, in China, Long, Naminse, Du, \& Zhuang, (2015) examined the association between renewable energy, output growth, non-renewables and environmental degradation. The study used the data from the period of 1952 to 2012. Applying the econometrics of cointegration and dynamic regression, the outcomes of the study revealed that both form of energy utilizations are 
significant to influence output growth and environmental degradation. The results of causal investigation also suggested the presence of feedback causal relationship among the variables. In particular it is found that economic growth is bi-directionally linked to power utilization and environmental degradation in China.

Likewise, Dogan, \& Seker, (2016a) inspected the association of green energy, income, non-renewable power and environmental degradation. In order to measure degradation, the authors used the measure of carbon-di-oxide emanation. The study used the data of fifteen European Union nations from the period of 1980 to 2012. Applying the econometrics of panel DOLS and granger causality, the outcomes of the study revealed that green energy, trade, income and non-renewable energy are significant to influence carbon emanations in European region. In particular, the findings established the negative relationship between green energy and trade with environmental degradation and positive association between non-renewable and carbon emissions. Furthermore, the study also validated the EKC curve in the EU countries. As for the outcomes of causal investigation, the study confirmed the presence of bi-directional relationship among green energy and environmental degradation. On the other hand, the causal relationship between carbon-di-oxide and income stated the existence of uni-directional link from income to emission, carbon to non-renewables and trade liberalization to environmental degradation in EU nations.

In addition, Dogan, \& Seker, (2016b) also inspected the association of renewable energy, output growth, financial development, trade and environmental degradation. In order to measure degradation, the authors used the measure of carbon-di-oxide emanation. The study used the data of top carbon emitting economies from the period of 1985 to 2011. Applying the econometrics of panel cointegration, FMOLS and DOLS, the outcomes of the study revealed that renewable energy is significant to influence environmental degradation. Specifically, the findings established that increase in green energy, trade and financial advancements significantly reduce the carbon emanations in the sampled countries. Moreover, the results also supported the validity of EKC curve indicating an inverted U-shaped association. Lastly, the result also indicated that non-renewable power utilization brought positive impact in environmental degradation. In a time-series analysis, Menyah, \& Wolde-Rufael, (2010) analyzed the link between green energy, output growth, nuclear power and environmental degradation. In order to measure degradation, the authors used the measure of carbon-di-oxide emanation. The study used the time series data of United States from the period of 1960 to 2007. Applying the econometrics of granger causality, the outcomes of the study revealed that renewable energy has no causal association with carbon emanations, however, carbon emanation uni-directionally cause renewable consumption. As for nuclear energy, the granger results reported the presence of negative uni-directional causal association running from nuclear power to carbon.

In Italy, Bento, \& Moutinho, (2016) inspected the association of green energy, output growth, trade, non-renewable and environmental degradation. In order to measure degradation, the authors used the measure of carbon-di-oxide emanation. The study used the data from the period of 1960 to 2011. Applying the econometrics of ARDL bound testing and granger causality, the outcomes of the study revealed that renewable energy has significant negative impact on environmental degradation. Moreover, international trade is found to have negative significant impact on carbon emissions. The result of causal investigation also suggested the causal connection of trade with environmental degradation and non-renewables production. Moreover, it was also found that output and non-renewable have uni-directional causal connection with green energy production in Italy. As for Pakistan, Danish, Zhang, Wang, \& Wang, (2017) investigated the association of renewable energy and non-renewable energy with environmental degradation. In order to measure degradation, the authors used the measure of carbon-di-oxide emanation. The study used the data from the period of 1970 to 2012. Applying the econometrics of ARDL, FMOLS and DOLS, the outcomes of the study revealed that both renewable and non-renewable powers are the significant drivers of environmental degradation. Specifically, the findings established that increase in green energy is vital to reduce the carbon emanation, but non-renewable consumption brought positive impact on environmental degradation. Moreover, the results also supported the validity of EKC curve indicating an inverted U-shaped association. The results of causal investigation also suggested the presence of causal relationship among the variables. It is found that both green energy and non-renewable energy have bi-directional causal association with environmental degradation in Pakistan.

Inglesi-Lotz, \& Dogan, (2018) also inspected the association of green energy, output, trade and non-renewables with environmental degradation. In order to measure degradation, the authors used the measure of carbon-di-oxide emanation. The study used the data of ten SSA nations from the period of 1980 to 2011. Applying the econometrics of panel cointegration, the outcomes of the study revealed that green energy is significant to influence environmental degradation. Similarly, non-renewable power consumption is also found to significantly influence carbon emanations in SSA countries. Specifically, the findings established that increase in green energy is vital to reduce the carbon emanations, whereas, non-renewable brought increase in ecological degradation. Moreover, the results also 
supported the validity of EKC curve indicating an inverted U-shaped association. The results of causal investigation also suggested the presence of uni-directional causal relationship among from carbon and non-renewables to green energy, carbon and non-renewables to trade \& from carbon, output, trade and non-renewable to green energy in the sampled countries (Jermsittiparsert, Sriyakul \& Pamornmast, 2014).

In Tunisia, Jebli, \& Youssef, (2015) also studied the association between green energy utilization, output growth and environmental degradation. Using the proxy if carbon-di-oxide to measure degradation, the authors used the data from the period of 1980 to 2009. Applying the methods of ARDL bound testing and VECM, the findings established of the study revealed that green energy and non-renewable energy are significant to influence environmental degradation. Specifically, the findings established that increase in green energy marginally declined carbon emanations, however non-renewables significantly enhanced it. Moreover, the results of the study failed to find the validity of EKC curve for the case of Tunisia. The results of causal investigation also suggested the existence of the causal relationship among the variables. Similar to Apergis, \& Payne, (2015), the findings established the presence of feedback effect among green energy and carbon emanations. As in Malaysia, Gill, Viswanathan, \& Hassan, (2017) aimed to explore to association of renewable energy and output with greenhouse gas (GHG) emanation. In order to measure GHG, the authors used the measure of carbon-di-oxide emissions. The study used the data of seventeen OECD nations from the period of 1970 to 2011. Applying the econometrics of ARDL, the findings of the analysis stated that green energy is significant to influence GHG emissions. In particular, the findings established that increase in green energy is vital to reduce the carbon emanations in Malaysia. On the other hand, the outcomes of the study failed to find the validity of EKC curve for the case of Malaysia indicating that mere dependence on economic development is insufficient to reduce ecological degradation (Haseeb, Abidin, Hye \& Hartani, 2018).

Furthermore, Jebli, \& Youssef, (2017) also examined the link between green energy, agriculture and environmental degradation in North Africa. In order to measure degradation, the authors used the measure of carbon-di-oxide emanation. The study used the data of five North African economies from the period of 1980 to 2011. Applying the econometrics of panel OLS, FMOLS and DOLS, the outcomes of the study revealed that renewable energy is significant to influence environmental degradation. However, unlike Bento, \& Moutinho, (2016); Inglesi-Lotz, \& Dogan, (2018); Zoundi, (2017), the findings established that increase in green energy is likely to further enhance the levels of carbon emanations in North Africa. The result further established that agriculture is a significant driver that can be used to reduce environmental degradation. In Algeria, Bélaïd, \& Youssef, (2017) investigated the connection between green energy, non-renewable energy, output and environmental degradation. In order to measure degradation, the authors used the measure of carbon-di-oxide emanation utilizing the data from the period of 1980 to 2012. Applying the econometrics of ARDL approach, the findings of the study revealed that renewable energy is significant to influence environmental degradation. Moreover, the results also supported the significant association of output and non-renewables with carbon emanations of the country. Specifically, the findings established that increase in green energy is vital to reduce the carbon emanations, however, non-renewables augmented ecological degradation. Moreover, the results also supported the validity of EKC curve indicating an inverted U-shaped association. The results of causal investigation also suggested the presence of causal relationship among energy consumption and degradation. It is found that both green energy and non-renewable power consumption led the causal association towards carbon emanation in Algeria.

\section{Methodology}

In the current examination, we utilize yearly information of green energy utilization, globalization, agriculture production, economic growth and carbon dioxide emission. Renewable energy utilization is used as a proxy of green energy which is represented by (GE). Moreover, economic globalization index is used as a proxy of globalization which is explained by (GLO). Also, gross domestic product is used as a proxy of economic growth denoted by (GDP). In addition we used agriculture production which is explained as (AGP) and finally carbon dioxide emission is used as a proxy of environmental degradation which is used as a (CO2). The data of economic globalization index is collected from the website of KOF Globalization Index. However, the information of renewable energy consumption, gross domestic product, agriculture production and carbon dioxide emission are collected from the website of World Bank (World Development Indicator). Current investigation is analyzing the effect of green energy, agriculture production, economic growth and globalization on environmental degradation in 40 sub-Saharan African nations. In the current investigation, we utilize green energy, economic growth, agriculture production and globalization as determinants of carbon dioxide emission in different sub-Saharan African countries. Additionally, the current investigation covers the time range from 1995 to 2017 for selected sub-Saharan nations. In the current investigation, the carbon dioxide emission is exhibited according to the below equation: 


$$
C O 2_{i t}=f\left(G E_{i t}, G L O_{i t}, A G P_{i t}, G D P_{i t}\right)
$$

Where, $\mathrm{CO} 2$ it is the carbon dioxide emission and measure in (kilo tons of oil equivalent), GEit is green energy utilization and measured as renewable energy consumption out of total energy consumption. GLOit is globalization index which is measured by economic globalization, AGPit is measured as agriculture production and GDPit is the economic growth which is measured from the total finished goods and services (US dollars). At long last, i speaks about the numbers of nations use in the current study and t explains the timeframe of the current investigation. In the recent study, we explore the long-term connection among the factors by consuming a panel long-run relationship. Correspondingly, current study explains the long-run impact of green energy utilization, globalization, agriculture production and economic growth on carbon dioxide emission by utilizing FMOLS and DOLS approaches. At last, we utilize a new method of heterogeneous panel causality analysis to deal with inspect the possible causal connection among green energy utilization, globalization, economic growth, agriculture production and carbon dioxide emission in 40 sub-Saharan African countries.

\section{Data Analysis and Discussion}

\subsection{Descriptive Statistics}

Primarily, we investigate the essential statistics of the selected number of sub-Saharan nations. The outcome associated to the estimations is displayed in Table 1. As saw from the table the most noticeable estimation of mean of $\mathrm{CO} 2$ is 38275.678 with the maximum value of 44539.496 and the minimum value of 18243.677 . The mean value for the selected countries of GE is 1827.1478 and maximum value is 2249.324 while the minimum value is 1756.878 . Besides, the most noteworthy estimation of GLO is 59.479 with the minimum value of 24.648 and maximum value is 84.779. Also, the AGP mean value is 4217.248 with the minimum value of 3154.116 and the maximum value of 4971.159. Finally, the average value for the sampled countries of GDP is 3824.593 with the minimum value of 2923.438 and maximum value of 5202.493. The standard deviation of all the selected variables is positive.

Table 1. Descriptive statistics of the variables

\begin{tabular}{llllll}
\hline Variables & Mean & Max & Min & Std. Dev. & Obs. \\
\hline Full Sample & & & & \\
\hline CO2 & 38275.678 & 44539.496 & 18243.677 & 183.214 & 920 \\
\hline GE & 1827.148 & 2249.324 & 1756.878 & 18.355 & 920 \\
\hline GLO & 59.479 & 84.779 & 24.648 & 10.326 & 920 \\
\hline AGP & 4217.247 & 4971.159 & 3154.116 & 17.462 & 920 \\
\hline GDP & 3824.593 & 5202.493 & 2923.438 & 14.479 & 920
\end{tabular}

Note: $\mathrm{CO} 2$ is the carbon dioxide emission, GE is the green energy utilization, GLO is the globalization, AGP is the agriculture production and GDP is the economic growth.

Source: Authors' Estimation

\subsection{Panel Unit Root Tests}

In the current study, we use IM, Pesaran and Shin (2003) and Levin, Lin and Chu (2002) unit root test which focusses on the theory of integration of variables. This panel unit root test is the key to apply panel long run relationship systems. This methodology is utilized to research the pattern of integration of the components. For example, if every single chosen factor are not stationary of the level, for instance $\mathrm{I}(0)$, by then this implies the majority of the variables have a unit root issue at level and are stationary at first differential arrangement. Consequently, it might be observed that all the chose variable in the present examination might have a connection in the longer-term period. 
Table 2. Results of stationary test

\begin{tabular}{|c|c|c|c|c|c|c|c|c|}
\hline \multirow{3}{*}{ Variables } & \multicolumn{4}{|c|}{ IM, Pesaran and Shin } & \multicolumn{4}{|c|}{ Levin, Lin and Chu } \\
\hline & \multicolumn{2}{|l|}{$\mathbf{I}(\mathbf{0})$} & \multicolumn{2}{|l|}{ I(1) } & \multicolumn{2}{|l|}{$\mathbf{I}(\mathbf{0})$} & \multicolumn{2}{|l|}{ I(1) } \\
\hline & $\mathbf{C}$ & C\&T & $\mathbf{C}$ & C\&T & $\mathbf{C}$ & C\&T & $\mathbf{C}$ & C\&T \\
\hline $\mathrm{CO2}$ & 0.456 & 0.431 & $-4.114 * * *$ & $-4.123 * * *$ & 0.401 & 0.407 & $-4.483 * * *$ & $-4.389 * * *$ \\
\hline GE & 0.789 & 0.715 & $-4.445 * * *$ & $-4.378 * * *$ & 0.698 & 0.701 & $-4.225 * * *$ & $-4.887 * * *$ \\
\hline GLO & 0.407 & 0.441 & $-5.140 * * *$ & $-5.113 * * *$ & 0.441 & 0.487 & $-4.136 * * *$ & $-4.445 * * *$ \\
\hline AGP & -0.443 & -0.403 & $-5.502 * * *$ & $-5.599 * * *$ & -0.397 & -0.412 & $-5.117 * * *$ & $-5.349 * * *$ \\
\hline GDP & 0.114 & 0.189 & $-4.443 * * *$ & $-4.398 * * *$ & 0.138 & 0.201 & $-5.249 * * *$ & $-5.330 * * *$ \\
\hline
\end{tabular}

Single, double, and triple asterisks indicate significance level respectively at 1,5 , and $10 \%$.

Source: authors' estimation

Table 2 describes the outcomes for the Levin, Lin and Chu (2002) and Im, Pesaran and Shin (2003) unit root test. The unit root test results for the 40 sub-Saharan countries exhibit that the dismissal of the null hypothesis of unit root test at the $1 \%$ significance level for all variables, implying that each of the variable are non-stationary at level and become stationary at first differential series. Therefore, the results of unit root confirm that each of the selected variables are showing up non-stationary property at the level series and exhibiting stationary properties at the first difference stage. In general, all components are integrated at I(1). Thusly, there must be a sign of long-run association between the components in long run.

\subsection{CD and CIPS Test}

At second stage, we check that which of the variable has the features for cross-sectional dependence or independence. This is the serious reason which should be unraveled before applying to basic estimations. The traditional unit root test has low power and is not viable when they are utilized on the panel estimations which as of now has a cross-sectional reliance problem (Bhattacharya et al., 2016; Sharif et al., 2019). Thus, in current investigation, we also utilize Pesaran (2007) CIPS unit root test which depends on the theory of cross-sectional reliance. This test is utilized to inspect the order of joining of the factors. On the other hand, if whole factors are coordinated of the equivalent level for example I(1), at that point this means whole of the informational collection has a unit root issue at level and are stationary at first differential series. In this way, it tends to be finished up that all factors in the informational collection may have a relationship in long-run symmetry.

Table 3. Results of cross-sectional dependence and cips unit root test

\begin{tabular}{lllll}
\hline \multirow{2}{*}{ Variable } & CD test & p-value & \multicolumn{2}{c}{ CIPS test } \\
\cline { 2 - 5 } CO2 & & & Level & 1st difference \\
\hline GE & 27.472 & 0.0000 & -1.378 & $-5.248 * * *$ \\
\hline GLO & 37.456 & 0.0000 & -1.198 & $-4.248 * * *$ \\
\hline AGP & 21.497 & 0.0000 & -2.217 & $-5.079 * * *$ \\
\hline GDP & 35.571 & 0.0000 & -2.017 & $-5.453 * * *$ \\
\hline
\end{tabular}

Note: $* * *, * *, *$ indicates statistical significance at $1 \%, 5 \%$ \& $10 \%$.

Source: Authors' estimation.

Table 3 clarifies the results for the CD test and CIPS unit root test. The CD test results refused the invalid hypothesis of cross area independence, meaning sign of cross-sectional reliance among the dataset. We also utilized recently introduced CIPS unit root test. This test talks about for cross-sectional reliance in the information series. The results of the CIPS unit root test demonstrate that the refusal of the invalid hypothesis for all factors at first differentials. In this way, there must be a proof of cointegration connection between the factors in long-term equilibrium. 


\subsection{Panel Cointegration Tests}

We additionally apply Kao (2003) and Pedroni (2004) panel long-run relationship procedures to investigate the long haul connection between green energy consumption, economic growth, globalization, agriculture production and carbon dioxide emission in sub-Saharan African countries. So as to run this approach, every factor ought to be stationary at first differential for example I(1). In the present investigation, we also utilize bootstrap cointegration introduced by Westerlund (2007) to analyze the long-term connection between the factors all through the total sample of 40 sub-Saharan countries. This examination is increasingly valuable if the time arrangement segment of each cross-segment is lesser. Inferable from these highlights look into researchers have recently adopting the bootstrapping long run relationship method to explore the long term connection among different factors (Sharif et al. 2019). The results reveal that these tests have limiting normal distribution and they are progressively dependable in term of constancy. Westerlund (2007) clarifies that the results provide nice size correctness and are additionally influential that traditional cointegration test by Pedroni (2004). In light of this proof, present investigation will dissect the impact of green energy utilization, globalization, agriculture production and economic growth on carbon dioxide emission in sub-Saharan countries. In light of the existence of long-run relationship, the long-run estimation remains calculated. In a cross-sectional examination, the error fluctuation changes over the groups which effect the consistence of the parameters. So as to adapt up this issue the generalized least squares strategy (GLS) could be used. In any case, the difference consistency still happens, for example, the relationship of the squared residuals with the regressor in each group. As such, to deal with the issue giving the issue of heteroskedasticity, we finally apply fully modified ordinary least square (FMOLS) and dynamic ordinary least square (DOLS) strategy.

Table 4. Results of Pedroni (Engle-Granger based) panel cointegration

\begin{tabular}{|c|c|c|}
\hline Estimates & Stats. & Prob. \\
\hline \multicolumn{3}{|c|}{$\mathrm{CO2}=f(\mathrm{GE}+\mathrm{GLO}+\mathrm{AGP}+\mathrm{GDP})$} \\
\hline Panel v-statistic & -20.423 & 0.000 \\
\hline Panel rho-statistic & -18.247 & 0.000 \\
\hline Panel PP statistic & -12.248 & 0.000 \\
\hline Panel ADF statistic & -14.579 & 0.000 \\
\hline \multicolumn{3}{|c|}{ Alternative Hypothesis: Individual AR Coefficient } \\
\hline Group rho-statistic & -17.336 & 0.000 \\
\hline Group PP statistic & -67.247 & 0.000 \\
\hline Group ADF statistic & -34.247 & 0.000 \\
\hline
\end{tabular}

Note: The null hypothesis of Pedroni's (1997) panel cointegration procedure is no cointegration.

Source: Authors' estimation.

Table 4 defines the outcomes of Pedroni panel cointegration analysis results. This approach rejects the null hypothesis of no cointegration at all seven estimations of within estimation (Panel v-stats, Panel rho-stats, Panel PP stats and Panel ADF stats) and three estimations of the between group (group rho, PP stats and group ADF stats) second this rejection of no cointegration in the favor of alternative hypothesis. Consequently, seven tests disclose that the variables move together over the long haul relationship in green energy utilization, globalization, economic growth, agriculture production and carbon dioxide emission model.

Table 5. Results of Kao (Engle-Granger based) panel cointegration

\begin{tabular}{lll}
\hline Estimates & Stats. & Prob. \\
\hline CO2 $=\boldsymbol{f}($ GE + GLO + AGP + GDP $)$ & & \\
\hline Panel ADF-statistics & -97.453 & 0.000
\end{tabular}

Note: The null hypothesis of Kao residual co-integration panel co-integration procedure is no co-integration.

Source: Authors' estimation. 
The cointegration among all factors confirm by using the Kao test. As saw from the outcomes presented in Table 5, the null hypothesis is rejected and the alternative hypothesis is accepted, i.e., long-run relationship exists between green energy utilization, globalization, economic growth, agriculture production and carbon dioxide emission in the sub-Saharan African nations.

Table 6. Results of Westerlund (2007) bootstrap panel cointegration

\begin{tabular}{lllll}
\hline Statistic & Value & Z value & $\boldsymbol{p}$ value & Robust $\boldsymbol{p}$ value \\
\hline $\mathbf{G t}$ & -3.148 & -1.796 & 0.000 & 0.002 \\
\hline $\mathbf{G a}$ & -31.478 & -19.745 & 0.000 & 0.000 \\
\hline $\mathbf{P t}$ & -28.148 & -9.942 & 0.000 & 0.070 \\
\hline $\mathbf{P a}$ & -32.448 & -32.018 & 0.000 & 0.000 \\
\hline
\end{tabular}

Note: The null hypothesis of Westerlund (2007) panel cointegration procedure is no cointegration.

Using the boot strap approach of Westerlund (2007) to account for cross-sectional dependence, the number of replications is 1000 . The $\mathrm{p}$-values are for a one sided test based on normal distribution. The robust $\mathrm{p}$-value are for a one sided test based on 1000 bootstrapping replications.

Source: Authors' estimation.

The long-term relationship among the factors is also examined by utilizing the second-generation long-term cointegration test. The results regarding the panel long-run relationship estimations are presented in Table 6 . The outcomes also robust the approval of alternative hypothesis. Consequently, the advanced cointegration test also endorses that green energy, globalization, agriculture production, economic growth are cointegrated in the long-term symmetry in carbon emission framework.

\subsection{Long Run Estimations}

Previous investigation utilizes pooled conventional least squares (OLS) to look at the effect of considered variables. Moreover, Pedroni (2001a, 2001b) opposed that as a result of regression result, inconsistent controls could affect for the presence of sequential correlation and endogeneity issue among the regressor. Likewise, to deal with these issues, the present examination uses the FMOLS procedure. This system focuses on the non-parametric strategy so as to choose the issue of endogeneity and sequential correlation (Sharif et al, 2019). In like way, we use FMOLS and DOLS methodologies to examine the long haul association among green energy, globalization, agriculture production, economic growth and carbon dioxide emission in sub-Saharan countries.

The long-term connection between the variable is explained by utilizing the FMOLS and DOLS approaches. These approaches were displayed by Phillips and Hansen (1990) and sometime later adjusted by the Pedroni (2001). We select these methods since they talk about to autocorrelation and endogeneity issues and provide robust outcomes. Likewise, present study examines the long-term checks by reporting the FMOLS and DOLS estimates. The consequences of FMOLS and DOLS have been shown to in Table 7. The long-run coefficient evaluated utilizing two novel strategies which are particularly proportional and basic at the $10 \%$ essentialness level. The results of FMOLS and DOLS attest that every one of the determinants of carbon dioxide emission in the 40 sub-Saharan African countries. The consequences of the long-run coefficient further recommend that every one of the determinants considered in this investigation significantly affect carbon dioxide emission in sub-Saharan African nations.

Table 7. Results of long-run estimation through FMOLS and DOLS

\begin{tabular}{lllllll}
\hline \multirow{2}{*}{ Variable } & FMOLS & \multicolumn{5}{c}{ DOLS } \\
\cline { 2 - 7 } & Coeff. & t-stats & Prob. & Coeff. & t-stats & Prob. \\
\hline GE & -0.432 & -4.421 & 0.000 & -0.410 & -4.402 & 0.000 \\
\hline GLO & 0.304 & 4.324 & 0.000 & 0.312 & 4.119 & 0.000 \\
\hline AGP & 0.282 & 3.875 & 0.000 & 0.274 & 3.899 & 0.000 \\
\hline GDP & -0.311 & -5.579 & 0.000 & -0.308 & -5.523 & 0.000 \\
\hline
\end{tabular}

Source: Authors Estimation 
Table 7 explain that the outcomes of panel estimations confirm that the long-term effect on carbon dioxide by green energy utilization to -0.432 explain that a per unit variation in the green energy utilization will help to reduce carbon dioxide emission by 0.432 unit. The outcomes further suggested that globalization and agriculture production have also a significant and positive impact on carbon dioxide emission. The outcomes confirm that a per unit increase in globalization (agriculture production) causes 0.304 (0282) unit change in carbon dioxide emission. Finally, results also confirmed that economic growth has also negative and significant impact on carbon dioxide emission. Results suggested that a per unit increase in economic growth causes 0.311 unit decrease in carbon dioxide emission in sub-Saharan countries. In general, the consequences of FMOLS and DOLS affirm that green energy utilization, globalization, agriculture production and economic growth are the critical and noteworthy determinants of carbon dioxide emission in sub-Saharan African nations. The outcomes recommend that sub-Saharan countries need an environmental efficient energy utilization and sustainable economic development which is free of carbon pollution when they are cooperating with other countries. The outcomes additionally affirmed that the more the green energy utilization and economic growth the lesser will be the carbon dioxide emission however, the more the globalization and agriculture production the higher the carbon dioxide emission in these sub-Saharan countries.

\subsection{Heterogeneous Panel Causality}

Moreover, in this present examination for scrutinizing the causal relationship among the factors, we examine the short-run underlying association among the components by picking a structure that cares the heterogeneity of the model all through the cross-areas. Besides, this panel causality strategy has presented by Dumitrescu and Hurlin (2012). Current framework is proper for stationary variables by utilizing the constant estimations in the vector autoregressive (VAR) system. The consequences of this method are that it's utilizing diverse log arrangement and relatively various estimation all through the cross-section beneath the all norms. Essentially, the null theory of no causal affiliation is inspected and after that the alternative theory for examining the causal association for minimal cross sections. At last, the Wald test are enlisted to every of the cross sections independently to test Granger non-causality. Besides, Dumitrescu and Hurlin (2012) contended that the present heterogenous causality method fulfils a typical distribution in standardized non-causality supposition when $\mathrm{T}$ shows to unlimited group and thereafter $\mathrm{N}$ communicates to time interminable.

Table 8. Results of heterogeneous panel causality test

\begin{tabular}{lll}
\hline Null Hypothesis & Zbar-Stat & Prob. \\
\hline GE does not homogeneously cause CO2 & 14.438 & 0.000 \\
\hline CO2 does not homogeneously cause GE & 9.213 & 0.000 \\
\hline GLO does not homogeneously cause CO2 & 10.789 & 0.000 \\
\hline CO2 does not homogeneously cause GLO & 13.278 & 0.000 \\
\hline AGP does not homogeneously cause CO2 & 16.249 & 0.000 \\
\hline CO2 does not homogeneously cause AGP & 27.198 & 0.000 \\
\hline GDP does not homogeneously cause CO2 & 8.879 & 0.000 \\
\hline CO2 does not homogeneously cause GDP & 9.156 & 0.000 \\
\hline
\end{tabular}

Source: Authors Estimation

Finally, we apply the heterogeneous panel causality to check the causal association among the green energy, globalization, economic growth, agriculture production and carbon dioxide emissions. The outcome is explained in Table 8. The results show that a bidirectional causal connection occurs between the green energy and carbon dioxide emission and the causality is running from green energy to carbon dioxide emission and running from carbon dioxide emission to green energy. Similarly, in the carbon dioxide emission and globalization model, outcome signifies a bi-directional causal connection occurs between globalization and carbon dioxide emission. Results further suggest a bi-directional causal relationship between agriculture production and carbon dioxide emission and economic growth and carbon dioxide emission in the group of sub-Saharan African countries. 


\section{Conclusion}

Witnessing the growing global warming and deteriorating environmental condition, the economies at present are facing enormous pressures for pursuing economic advancements along with sustainable ecological environment. In this regard, the contribution of energy is considered critical for aiding the process of economic development, however, carrying multiple adverse effects on the environment. The toxic emissions resulted from the burning of fossil fuels and other non-renewable forms of energy such as natural gas, gasoline, heating oil etc., in several industrial processes put enormous pressure on the environment by releasing carbon-di-oxide, sulphur dioxide, dust \& aerosols, nitrogen oxides, steam-laden emanations along with damaging ozone layer. Thus, understanding the crucial role of green energy and agriculture in influencing environmental health, the present study aims to examine the impact of green energy consumption and agriculture value added on environmental degradation in Sub-Saharan African region.

The significance of current study is attributed in identifying the eminent role of renewable energy utilization in changing the levels of toxic carbon emission in the sampled nations. Furthermore, the methodological contribution in the current examination is also notable in applying advanced methods to explore the critical association among the variables of interest. In doing so, the current investigation applied the econometrics of panel FMOLS and DOLS along with examining the cross-sectional dependence and Bootstrap cointegration. The results of the long-run estimations of FMOLS and DOLS suggested that the green energy utilization has a negative impact on environmental hazards and support to decrease environmental hazards. Likewise, globalization has a positive and noteworthy effect on environmental hazards. Also, the agriculture productions also play a significant and positive impact on environmental degradation. Finally, the heterogeneous panel causality confirms a bi-directional causal relationship between green energy consumption, globalization, agriculture production and economic growth with environmental degradation in all sub-Saharan African countries.

\section{References}

Akella, A. K., Saini, R. P., \& Sharma, M. P. (2009). Social, economical and environmental impacts of renewable energy systems. Renewable Energy, 34(2), 390-396. https://doi.org/10.1016/j.renene.2008.05.002

Amankwah-Amoah, J. (2015). Solar energy in sub-Saharan Africa: The challenges and opportunities of technological leapfrogging. Thunderbird International Business Review, 57(1), 15-31. https://doi.org/10.1002/tie.21677

Amponsah, N. Y., Troldborg, M., Kington, B., Aalders, I., \& Hough, R. L. (2014). Greenhouse gas emissions from renewable energy sources: A review of lifecycle considerations. Renewable and Sustainable Energy Reviews, 39, 461-475. https://doi.org/10.1016/j.rser.2014.07.087

Apergis, N., \& Payne, J. E. (2010). Renewable energy consumption and economic growth: evidence from a panel of OECD countries. Energy Policy, 38(1), 656-660. https://doi.org/10.1016/j.enpol.2009.09.002

Apergis, N., \& Payne, J. E. (2015). Renewable energy, output, carbon dioxide emissions, and oil prices: evidence from South America. Energy Sources, Part B: Economics, Planning, and Policy, 10(3), 281-287.

Arcanjo, M. (2018). Revolutionizing Renewables in Sub-Saharan Africa. Climate Institute. Retrieved from http://climate.org/revolutionising-renewables-in-sub-saharan-africa

Bélaïd, F., \& Youssef, M. (2017). Environmental degradation, renewable and non-renewable electricity consumption, and economic growth: Assessing the evidence from Algeria. Energy Policy, 102, 277-287.

Bento, J. P. C., \& Moutinho, V. (2016). CO2 emissions, non-renewable and renewable electricity production, economic growth, and international trade in Italy. Renewable and Sustainable Energy Reviews, 55, 142-155.

Bhattacharya, M., Paramati, S. R., Ozturk, I., \& Bhattacharya, S. (2016). The effect of renewable energy consumption on economic growth: Evidence from top 38 countries. Applied Energy, 162, 733-741.

Bilgili, F., Koçak, E., \& Bulut, Ü. (2016). The dynamic impact of renewable energy consumption on CO2 emissions: a revisited Environmental Kuznets Curve approach. Renewable and Sustainable Energy Reviews, 54, 838-845.

Bosselmann, K. (2016). The principle of sustainability: transforming law and governance. Routledge.

Danish, Zhang, B., Wang, B., \& Wang, Z. (2017). Role of renewable energy and non-renewable energy consumption on EKC: evidence from Pakistan. Journal of Cleaner Production, 156, 855-864.

Deichmann, U., Meisner, C., Murray, S., \& Wheeler, D. (2011). The economics of renewable energy expansion in rural Sub-Saharan Africa. Energy Policy, 39(1), 215-227. https://doi.org/10.1016/j.enpol.2010.09.034 
Dogan, E., \& Seker, F. (2016a). Determinants of CO2 emissions in the European Union: The role of renewable and non-renewable energy. Renewable Energy, 94, 429-439. https://doi.org/10.1016/j.renene.2016.03.078

Dogan, E., \& Seker, F. (2016b). The influence of real output, renewable and non-renewable energy, trade and financial development on carbon emissions in the top renewable energy countries. Renewable and Sustainable Energy Reviews, 60, 1074-1085. https://doi.org/10.1016/j.rser.2016.02.006

Dumitrescu, E. I., \& Hurlin, C. (2012). Testing for Granger non-causality in heterogeneous panels. Economic Modelling, 29(4), 1450-1460. https://doi.org/10.1016/j.econmod.2012.02.014

Gill, A. R., Viswanathan, K. K., \& Hassan, S. (2017). A test of environmental Kuznets curve (EKC) for carbon emission and potential of renewable energy to reduce green house gases (GHG) in Malaysia. Environment, Development and Sustainability, 1-12. https://doi.org/10.1007/s10668-017-9929-5

Haseeb, M., Abidin, I. S. Z., Hye, Q. M. A., \& Hartani, N. H. (2018). The Impact of Renewable Energy on Economic Well-Being of Malaysia: Fresh Evidence from Auto Regressive Distributed Lag Bound Testing Approach. International Journal of Energy Economics and Policy, 9(1), 269-275.

Im, K. S., Pesaran, M. H., \& Shin, Y. (2003). Testing for unit roots in heterogeneous panels. Journal of Econometrics, 115(1), 53-74. https://doi.org/10.1016/S0304-4076(03)00092-7

Inglesi-Lotz, R., \& Dogan, E. (2018). The role of renewable versus non-renewable energy to the level of CO2 emissions a panel analysis of sub-Saharan Africa's Big 10 electricity generators. Renewable Energy, 123, 36-43. https://doi.org/10.1016/j.renene.2018.02.041

Jebli, M. B., \& Youssef, S. B. (2015). The environmental Kuznets curve, economic growth, renewable and non-renewable energy, and trade in Tunisia. Renewable and Sustainable Energy Reviews, 47, 173-185.

Jebli, M. B., \& Youssef, S. B. (2017). The role of renewable energy and agriculture in reducing CO2 emissions: Evidence for North Africa countries. Ecological Indicators, 74, 295-301.

Jermsittiparsert, K., Sriyakul, T., \& Pamornmast, C. (2014). Minimum Wage and Country's Economic Competitiveness: An Empirical Discourse Analysis. The Social Sciences, 9(4), 244-250.

Leonidou, L. C., Fotiadis, T. A., Christodoulides, P., Spyropoulou, S., \& Katsikeas, C. S. (2015). Environmentally friendly export business strategy: Its determinants and effects on competitive advantage and performance. International Business Review, 24(5), 798-811. https://doi.org/10.1016/j.ibusrev.2015.02.001

Levin, A., Lin, C. F., \& Chu, C. S. J. (2002). Unit root tests in panel data: asymptotic and finite-sample properties. Journal of Econometrics, 108(1), 1-24. https://doi.org/10.1016/S0304-4076(01)00098-7

Liu, X., Zhang, S., \& Bae, J. (2017). The impact of renewable energy and agriculture on carbon dioxide emissions: Investigating the environmental Kuznets curve in four selected ASEAN countries. Journal of Cleaner Production, 164, 1239-1247. https://doi.org/10.1016/j.jclepro.2017.07.086

Long, X., Naminse, E. Y., Du, J., \& Zhuang, J. (2015). Nonrenewable energy, renewable energy, carbon dioxide emissions and economic growth in China from 1952 to 2012. Renewable and Sustainable Energy Reviews, 52, 680-688. https://doi.org/10.1016/j.rser.2015.07.176

Menyah, K., \& Wolde-Rufael, Y. (2010). CO2 emissions, nuclear energy, renewable energy and economic growth in the US. Energy Policy, 38(6), 2911-2915. https://doi.org/10.1016/j.enpol.2010.01.024

Mittal, S., Dai, H., Fujimori, S., \& Masui, T. (2016). Bridging greenhouse gas emissions and renewable energy deployment target: comparative assessment of China and India. Applied Energy, 166, 301-313.

Ocal, O., \& Aslan, A. (2013). Renewable energy consumption-economic growth nexus in Turkey. Renewable and Sustainable Energy Reviews, 28, 494-499. https://doi.org/10.1016/j.rser.2013.08.036

Olowa, O. W. (2018). Determinants of Rural Residential Solid Waste Collection Services in Lagos State. International Journal of Sustainable Development \& World Policy, 7(1), 1-7.

Olufemi, A. S. (2018). Measuring and Assessing the State of Technological Innovations and the Level of Interaction between Rice Processors and Stakeholders in Rice Processing Industry in Nigeria. International Journal of Business, Economics and Management, 5(6), 164-175. https://doi.org/10.18488/journal.62.2018.56.164.175

Önder, M. (2018). Contribution of Plays and Toys to Children's Value Education. Asian Journal of Education and Training, 4(2), 146-149. https://doi.org/10.20448/journal.522.2018.42.146.149

Onyinye, I., Jonathan, E., \& Emmanuel, O. (2018). Foreign Capital Inflows and Unemployment in Nigeria: A New Evidence from ARDL-Bounds Testing Approach. International Journal of Business, 5(6), 176-188. 
Onyinye, I., Orji, A., Jonathan, E., \& Emmanuel, O. (2018). Disaggregated Foreign Capital Inflows and Economic Growth in a Developing Economy: Empirical Evidence from Nigeria. Journal of Empirical Studies, 5(1), 1-11.

Orji, A., Ogbuabor, J. E., \& Anthony-Orji, O. I. (2018). Macroeconomic Indicators and Capital Formation Growth in Nigeria: A New Evidence. Journal of Social Economics Research, 5(2), 39-50.

Orji, A., Ogbuabor, J. E., Okon, A. N., \& Anthony-Orji, O. I. (2018). Electronic Banking Innovations and Selected Banks Performance in Nigeria. The Economics and Finance Letters, 5(2), 46-57.

Osabohien, R., Osuma, G., Ndigwe, C., \& Ozordi, E. (2018). Social Protection and Agricultural Production in Ecowas: The Youth Unemployment Question. Journal of Social Economics Research, 5(2), 51-62

Paramati, S. R., Ummalla, M., \& Apergis, N. (2016). The effect of foreign direct investment and stock market growth on clean energy use across a panel of emerging market economies. Energy Economics, 56, $29-41$.

Pedroni, P. (2001a). Fully modified OLS for heterogeneous cointegrated panels. In Nonstationary panels, panel cointegration, and dynamic panels (pp. 93-130). Emerald Group Publishing Limited.

Pedroni, P. (2001b). Purchasing power parity tests in cointegrated panels. Review of Economics and Statistics, 83(4), 727-731. https://doi.org/10.1162/003465301753237803

Pedroni, P. (2004). Panel cointegration: asymptotic and finite sample properties of pooled time series tests with an application to the PPP hypothesis. Econometric Theory, 20(3), 597-625.

Pesaran, M. H. (2004). General diagnostic tests for cross section dependence in panels. CESifo Working Paper, No 1229. Center for Economic Studies and IFO Institute (CESifo), Munich.

Phillips, P. C., \& Hansen, B. E. (1990). Statistical inference in instrumental variables regression with I (1) processes. The Review of Economic Studies, 57(1), 99-125. https://doi.org/10.2307/2297545

Reganold, J. P., \& Wachter, J. M. (2016). Organic agriculture in the twenty-first century. Nature Plants, 2(2), 15221.

Sharif, A., Raza, S. A., Ozturk, I., \& Afshan, S. (2019). The dynamic relationship of renewable and nonrenewable energy consumption with carbon emission: A global study with the application of heterogeneous panel estimations. Renewable Energy, 133, 685-691. https://doi.org/10.1016/j.renene.2018.10.052

Sheahan, M., \& Barrett, C. B. (2017). Ten striking facts about agricultural input use in Sub-Saharan Africa. Food Policy, 67, 12-25. https://doi.org/10.1016/j.foodpol.2016.09.010

Sims, R. E., Rogner, H. H., \& Gregory, K. (2003). Carbon emission and mitigation cost comparisons between fossil fuel, nuclear and renewable energy resources for electricity generation. Energy Policy, 31(13), 1315-1326.

Wang, S. T. (2016). An Exploration of Sustainable Customer Value and the Procedure of the Intelligent Digital Content Analysis Platform for Big Data Using Dynamic Decision Making. Asian Journal of Economics and Empirical Research, 3(1), 25-31. https://doi.org/10.20448/journal.501/2016.3.1/501.1.25.31

Westerlund, J. (2007). Testing for error correction in panel data. Oxford Bulletin of Economics and Statistics, 69(6), 709-748. https://doi.org/10.1111/j.1468-0084.2007.00477.x

Widarjono, A. (2018). Maqasid Sharia Index, Banking Risk and Performance Cases in Indonesian Islamic Banks. Asian Economic and Financial Review, 1175-1184. https://doi.org/10.18488/journal.aefr.2018.89.1175.1184

Winarni, E. W., Purwandari, E. P., Lusa, H., \& Dadi, S. (2018). The Impact of Thematic Learning Integrated ICT in Tabot Bengkulu as Cultural Ceremony toward Social Interaction Knowledge in Elementary School. Asian Journal of Education and Training, 4(2), 70-74. https://doi.org/10.20448/journal.522.2018.42.70.74

World Bank. (2001). The World Bank’s Energy Program: Poverty Reduction, Sustainability, and Selectivity. Energy and Mining Sector Board Paper. World Bank, Washington, DC.

Xiaohua, W., \& Zhenmin, F. (2001). Rural household energy consumption with the economic development in China: stages and characteristic indices. Energy Policy, 29(15), 1391-1397.

Zhang, L., Zhou, H., Liu, Y., \& Lu, R. (2019). Optimal environmental quality and price with consumer environmental awareness and retailer's fairness concerns in supply chain. Journal of Cleaner Production, 213 , 1063-1079. https://doi.org/10.1016/j.jclepro.2018.12.187

Zoundi, Z. (2017). CO2 emissions, renewable energy and the Environmental Kuznets Curve, a panel cointegration approach. Renewable and Sustainable Energy Reviews, 72, 1067-1075. https://doi.org/10.1016/j.rser.2016.10.018 